\title{
A New Practical Approach for 3D Documentation in Ultraviolet Fluorescence and Infrared Reflectography of Polychromatic Sculptures as Fundamental Step in Restoration
}

\author{
Luca Lanteri ${ }^{1, *}$, Giorgia Agresti ${ }^{1,+}$ and Claudia Pelosi ${ }^{2,+}(\mathbb{C}$ \\ 1 Laboratory of Diagnostics and Materials Science "Michele Cordaro", University of Tuscia, 01100 Viterbo, \\ Italy; agresti@unitus.it \\ 2 Department of Economy, Engineering, Society and Business Organization, University of Tuscia, \\ 01100 Viterbo, Italy; pelosi@unitus.it \\ * Correspondence: llanteri@unitus.it; Tel.: +39-0761-357017 \\ + These authors contributed equally to this work.
}

Received: 20 December 2018; Accepted: 9 January 2019; Published: 15 January 2019

\begin{abstract}
The aim of this work is to present a new practical approach to digital photogrammetry to obtain 3D models of polychromatic sculptures under ultraviolet fluorescence and near-infrared by starting from photographic images. This digital photogrammetry was applied recently to a 17th-century reliquary bust representing St. Rodonio, a saint particularly venerated by the Orthodox Church, presently under restoration in the Laboratories of University of Tuscia and belonging to the Museum of Colle del Duomo of Viterbo (Italy). The acquisitions of ultraviolet fluorescence and infrared frames were performed using a Nikon D5300 digital SLR camera and a modified low-cost digital camera (Samsung Model NX3300), respectively. The three-dimensional UV and IR models were obtained using Agisoft PhotoScan ${ }^{\circledR}$ software. The generated ultraviolet 3D model of the bust makes visible, in a single file, the fluorescence induced by UV radiation on the entire sculpture, highlighting surface abrasions, organic dyes, and ancient protective features. The infrared 3D model allowed for better definition of the details of the drawing used for eyes, nose and mouth definition. In conclusion, the ultraviolet fluorescence and IR 3D models of Saint Rodonio were particularly useful as documentation tools for the conservation status and for the painting construction, allowing us to perfectly map the original and restoration materials and to detect the drawing in single dynamic 3D files following a totally non-invasive, cost-effective, and rapid approach.
\end{abstract}

Keywords: 3D documentation; digital photogrammetry; ultraviolet fluorescence photography; infrared photography; sculptures; restoration

\section{Introduction}

The aim of this paper is to report the potentiality of ultraviolet fluorescence (UVF) and infrared (IRR) photography applied on 3D models generated through digital photogrammetry. To our knowledge, this cost-effective approach was never applied to wooden polychromatic sculptures, but only to paintings, with the aim of investigating the surface layers [1,2]. Our application is completely different because it is applied to 3D objects to obtain easy-to-manage 3D models with UV fluorescence and infrared response that can be observed and rotated in pdf file format or at a specific link (as reported in the results), supplying a very useful instrument for conservators during the restoration phases. 
Documentation is a fundamental step in restoration, and it is the first indispensable process performed before starting and also during usual operations [3-10]. The relevance of documentation and condition records, including data acquisition, documents, graphics, and photographs, is stated in the standard UNI EN 16095 [11]. The condition record has historical value and contains all essential and relevant information in a logical and well-organized order [9]. In general, during the documentation process in restoration, it is common to use two-dimensional systems, such as photographs, textual notes, and graphical maps, to record the alteration, decay, additions, sampling points, etc. of artifacts and objects. However, the use of 3D digital models, especially in the case of sculptures or other 3D objects, gives some advantages [12-14]. The 3D models allow for the transferring of all information on a single file and permit the observation of the entire object surface by rotating the models [9].

The documentation step of the conservation processes often includes ultraviolet fluorescence and infrared photography that can supply additional information about the restored artifact [15]. UVF photography allows for the recording of images containing information on both constitutive and restoration materials that usually have different responses under UV radiation. The information gathered from these data is highly relevant in restoration because it gives the conservators knowledge of the original and restoration materials and so it supplies a valid aid for the cleaning operations generally aimed at removing superimposed or dirty layers [9]. The phenomenon is linked especially to organic materials, but also to inorganics; moreover, the intensity of fluorescence generally grows with ageing, so recent materials have less fluorescence, presenting as darker if compared to similar ancient materials $[9,16,17]$.

In the case of three-dimensional artworks, the traditional acquisition of UVF frames could represent a limit linked to the difficulty of showing, in a single 2D photogram, the details distributed in several focal planes. This drawback can be fixed using 3D photogrammetry and UV rendering starting from UVF images acquired with a traditional camera and processed with the Agisoft PhotoScan ${ }^{\circledR}$ software (Agisoft LLC, St. Petersburg, Russia) [18-20]. IR photography is also commonly used in the documentation phase of the restoration process, especially for paintings, in order to detect underdrawings, pentimenti, hidden signatures, etc. [21-23]. On the other hand, this technique, to our knowledge, was never applied to sculptures in order to obtain 3D models under infrared radiation.

For this reason, we tested the applied UVF and IR photography on a sculpture, in particular a wooden polychromatic bust representing Saint Rodonio (Figure 1), by using digital photogrammetry, a low-cost method that allows users to obtain 3D models of cultural heritage objects starting from still images [24-33]. This method permits the possibility of reaching millimeter-level accuracy through proper and well-known procedures [18,34-36]. The investigated bust, dated back to 17th century, is a reliquary, and may be connected to the cult of relics, i.e., the traditional practice of venerating the remains of the saint body, but also objects related to the life of the saint, which are considered as operative instruments of the Holy Spirit [37]. The reliquaries, therefore, represented the containers used to store, preserve and display the relics. They could have different shapes and be made of various materials such as metal, wood, paper-mâché, etc.

Reliquaries could be simple boxes characterized only by symbols or iconographic elements or objects with anthropomorphic appearances with clear references to the veneration of cult of relics, thus allowing an explicit connection to the saint or the martyr [38]. A clear example of this latter kind of reliquary is the bust of Saint Rodonio, a saint particularly venerated by the Orthodox Church, and the object of the present paper. The bust has been exposed in the Museum Colle del Duomo in Viterbo (Italy) since 2000 and is presently under restoration in the Laboratories of the University of Tuscia [38]. The bust, made of painted wood, has on its chest a small case closed by glass to collect the relic, now missing. There are clear signs of a faux silver porporina finishing applied on the surface in a past undocumented restoration, probably made of aluminum-based powder [38]. 


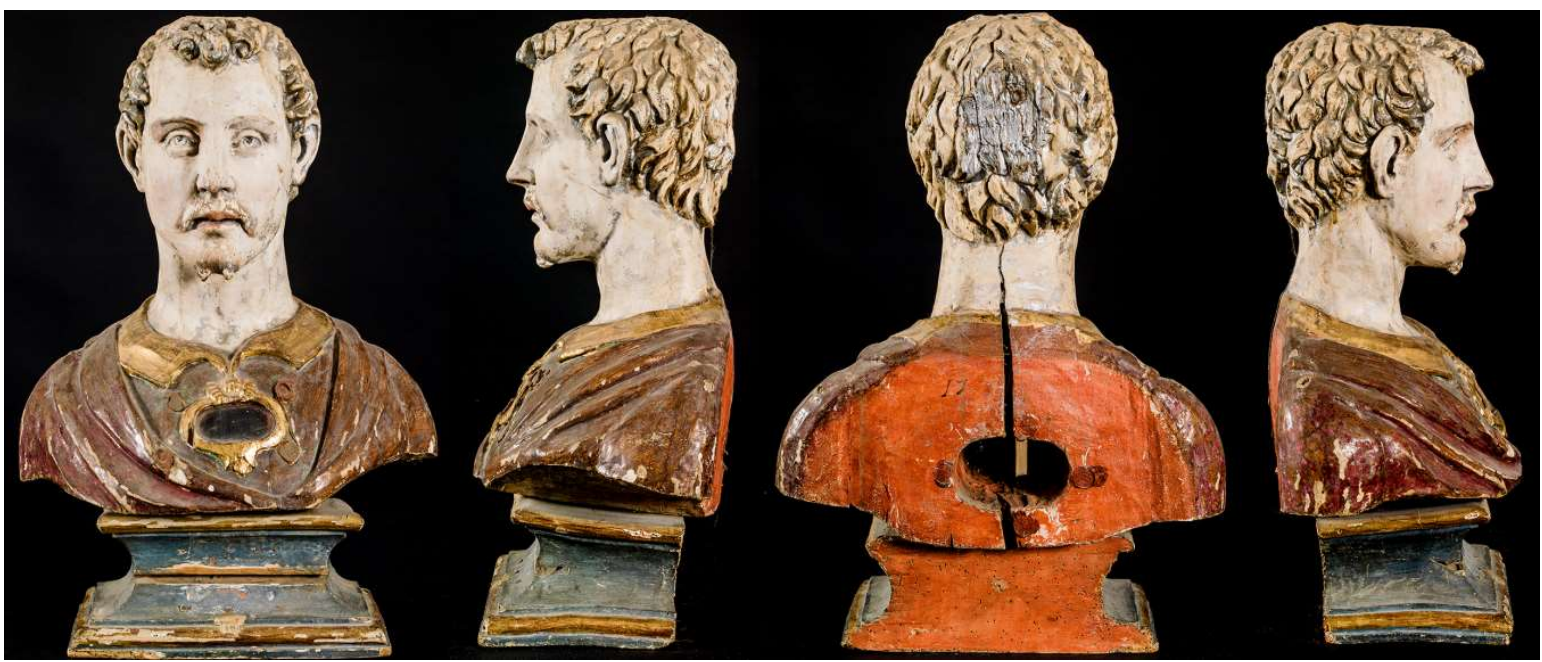

Figure 1. Visible images of the Saint Rodonio reliquary bust $(52 \times 37.5 \times 23 \mathrm{~cm}$; weight $6.6 \mathrm{~kg})$. The front, back, left, and right sides are shown.

\section{Materials and Methods}

The acquisition of ultraviolet fluorescence frames was performed using a Nikon D5300 digital SLR camera equipped with an $18 / 55 \mathrm{~mm}$ multifocal lens setting the following parameters: $\mathrm{f} / 4.8$, exposure time $2 \mathrm{~s}$, ISO-100 sensitivity, focal distance $38 \mathrm{~mm}$. UV irradiation was provided by Philips PHLTUV36 fluorescent tubes positioned at $45^{\circ}$ to the subject. On the camera optics, Kodak Wratten 2B filters (light yellow) and 85B (amber filter) were mounted in order to eliminate the reflections of the $\mathrm{UV}$ and to attenuate the dominant blue typical of ultraviolet shots. The camera and tubes are fixed during acquisition, and the object is rotated.

IR photography was performed using a modified low-cost digital camera Samsung Model NX3300 supplied by Madatec (MI-Italy). The camera was equipped with a zoom lens Pentax-A $50 \mathrm{~mm}$ at a maximum aperture of 2 . IR photographs were gathered under the following conditions: Exposure time $1 / 8 \mathrm{~s}$, ISO200, digital focal lens $35 \mathrm{~mm}$. In front of the camera lens, a filter was placed, cutting IR radiation at $950 \mathrm{~nm}$. The three-dimensional UV and IR models were obtained using Agisoft PhotoScan ${ }^{\circledR}$ software. Agisoft Photoscan ${ }^{\circledR}$ is a user-friendly software package providing a comprehensive Structure from Motion approach which integrates digital photogrammetry and the computer vision facilities with the ability to process unsorted photographs into photorealistic, geometrically-accurate, and georeferenced 3D models [34,39].

The technique allows for the generation of the 3D structure through the use of an image set acquired in a similar way to traditional photogrammetry, but with the advantage that the phases of the internal and relative orientation of the frames are completely automatized. SfM employs images overlapping and captured from multiple points of view with the further ability to simultaneously determine the internal geometry of the camera, its position, and orientation automatically. The high degree of overlapping of the frames, useful to cover the entire geometry of the object, gives rise to the name "structure derived from a motion sensor". The software workflow, after the upload of the photos, involves the use of the SIFT algorithm (Scale Invariant Feature Transform), developed by Lowe in 2004 [40]. It is able, through the use of image descriptors, to calculate and detect the positions throughout the image set of the homologous points (pixels) to sufficiently establish the spatial relationships within a relative $X Y Z$ coordinate system. Thus it arranges the photos according to the calculated parameters. Subsequently, the bundle adjustment algorithm controls and limits errors during the transformation of the coordinates of the 3D points taken from a cloud of points which is more or less dense depending on the number of detected key-points. 
The subsequent phase involves the generation of a dense cloud of points through the dense image matching algorithms. These are divided into two types: Area-based matching (AMB) algorithms that perform a statistical comparison of the intensity of grey tones detected on the images but which do not provide for the extraction of the features; and feature-based matching (FBM) algorithms that first look for common features and then extract them. The dense points cloud thus obtained is used to generate a polygonal model (mesh) that can be texturized to return a photorealistic 3D digital model.

The last step is related to the sizing of the model. For this reason, at the moment of acquisition of the images, a congruous number of targets whose spatial coordinates are known (in a local reference system) have been inserted into the scene. The model can also be sized by introducing scale bars into the scene to be photographed. Both systems contribute to the sizing of the model reaching within a millimeter of precision. The acquired frames were saved in .Jpg format with a resolution of $24 \mathrm{MP}$, sRGB 24-bit depth; each frame size was 5.80 MB. The images were processed on a workstation with the following features: Intel (R) Core processor (TM) i7-4770 CPU @ 3.40 GHz; Ram 32 Gb; 64-bit system, Windows $8.1^{\circledR}$; GeForce GTX $9704 \mathrm{~Gb}$ video card.

\section{Results}

\subsection{The 3D UVF Model}

The 3D model with ultraviolet fluorescence rendering performed before restoration allows for the localizing and characterizing of some materials and the general conservation status of the surfaces based on specific fluorescence responses (see Figure 2 and the model available at the link: https: //skfb.ly /6EMy7 on Sketchfab, a public platform to share 3D contents). From this platform, the model can be remotely visualized and rotated in 3D, allowing observers to see the entire bust surface under UV fluorescence. The model, observed and rotated in a pdf file generated directly by Agisoft PhotoScan ${ }^{\circledR}$, can be used by conservators with a local computer as a working file during the restoration activities.

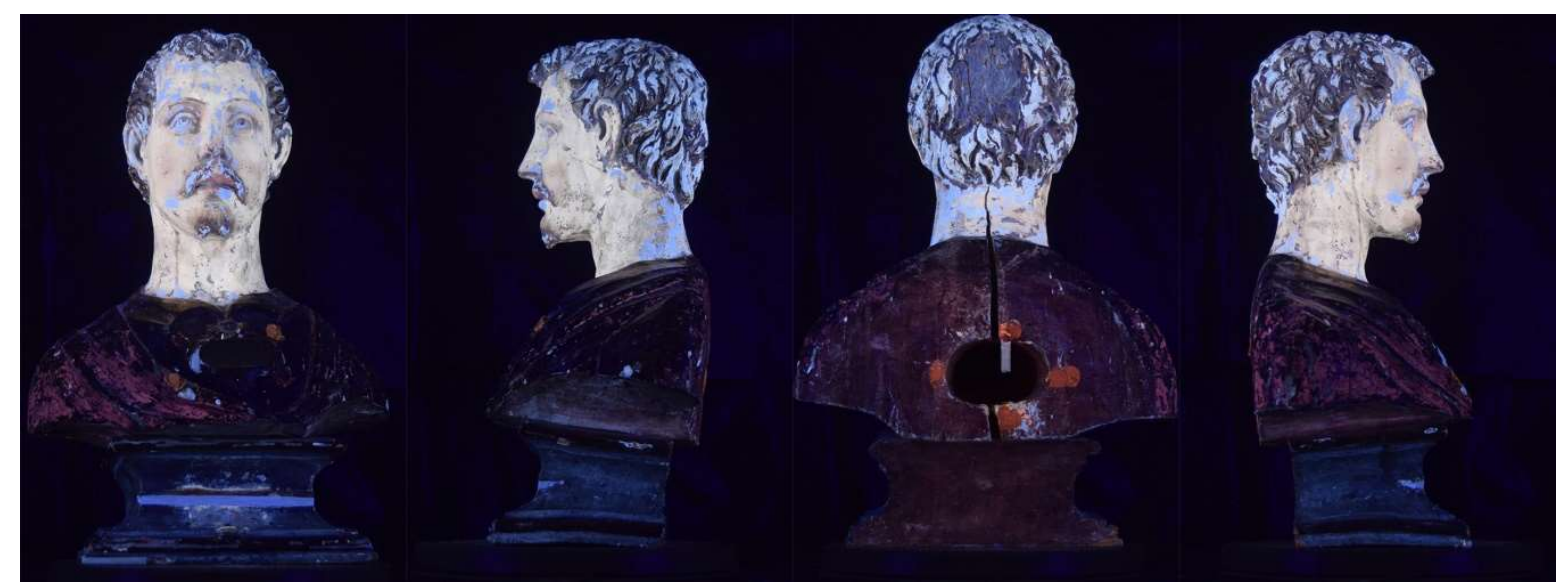

Figure 2. Some of the UV fluorescence images used for obtaining the 3D model. The front, back, left, and right sides are shown.

\subsection{The Near IR Model}

The 3D model with infrared rendering allows for the investigation of possible preparatory drawings used by the artist as a guide to paint the sculpture surfaces. Some views of the IR model are shown in Figure 3. Also, in this case, the model can be observed and rotated in a pdf file or accessed from the Sketchfab platform (see https://skfb.ly/6GoVv). The most interesting and relevant results from the IR images are displayed in Figure 4, showing details of the hair, nose, and beard. 


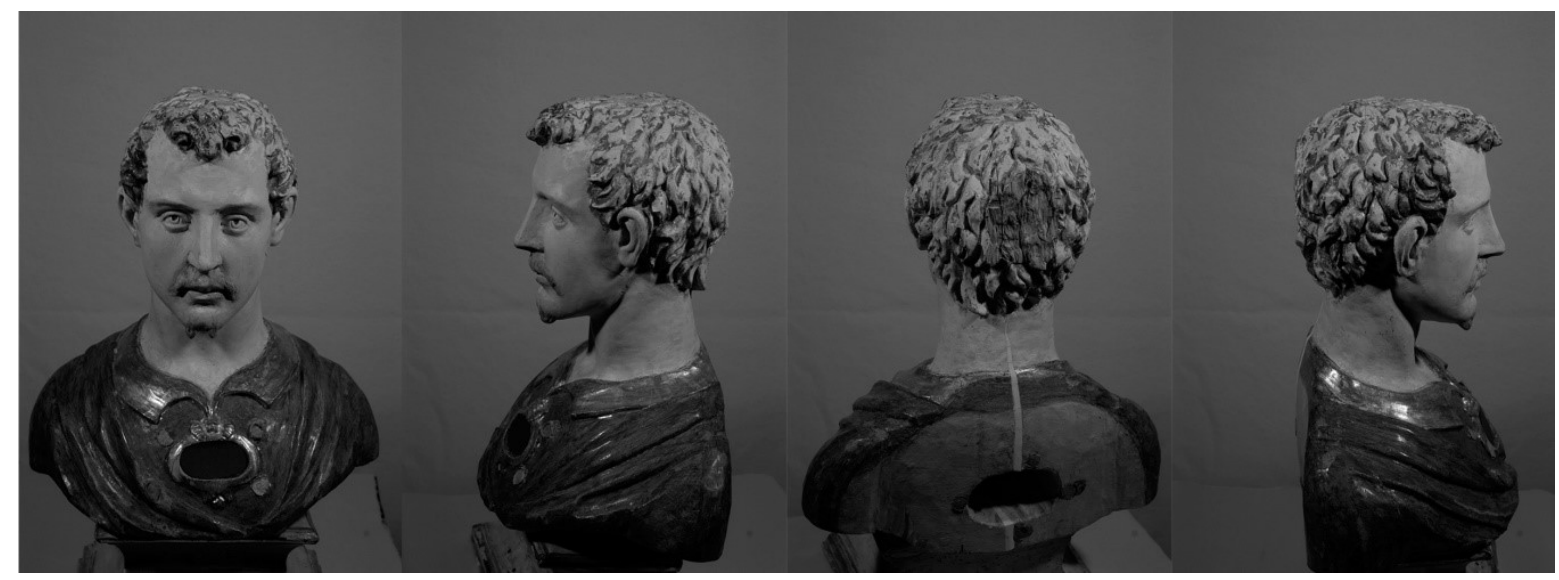

Figure 3. Some of the IR images used for the construction of the 3D model. The front, back, left, and right sides are shown.
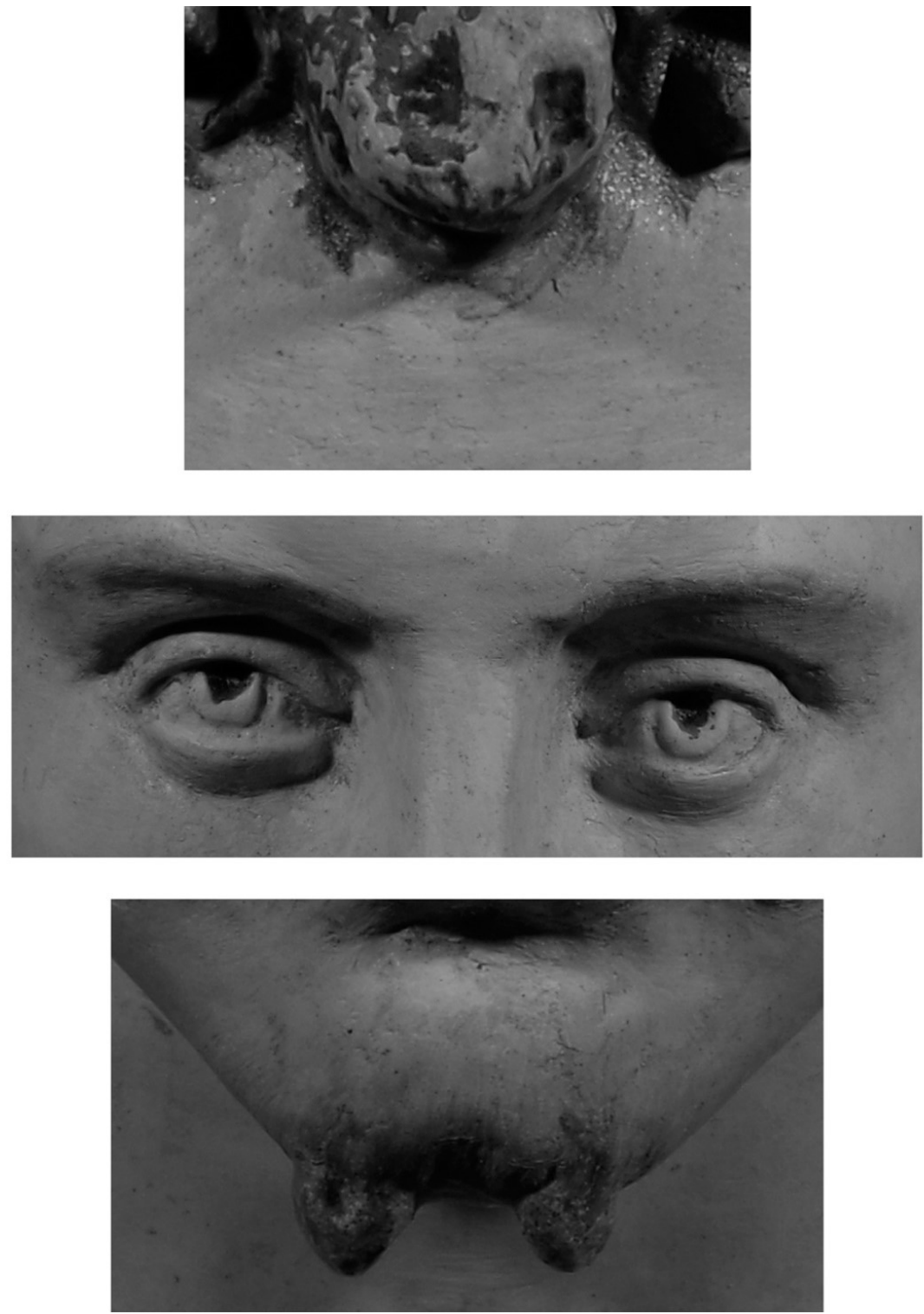

Figure 4. Details of St. Rodonio face (hair in the front, eyes, and beard on the chin) from IR images. 


\section{Discussion}

One of the main pieces of evidence revealed using 3D ultraviolet fluorescence can be seen in the numerous and widespread light blue areas that, if compared with the visible images, are located in correspondence with surface abrasions concentrated mainly on the hair, face, and neck of Saint Rodonio. These abrasions were probably caused by an aggressive past intervention (not documented) performed to remove the porporina layer that hid the original painting. In correspondence with the abrasions, the ground layer emerges from the painting layer, and it can be hypothesized that the light blue fluorescence is associated with the glue-binder mixed with gypsum, a traditional mixture used for preparing the wood surface before applying pigments [41,42]. A pale yellow fluorescence is clearly visible on the flesh areas probably due to the painting binder $[43,44]$. In some areas of the collar and of the base, a light orange fluorescence is observed which can be associated to a natural resin such as shellac, widely used in surface treatment of wooden sculptures [9,45-49]. An intense orange fluorescence is concentrated in four points of the front and back sides of the Saint Rodonio bust. This response is due to the wax used for sealing up the relic in the hollow of the bust. Lastly, the presence of a bright purple fluorescence in the drapery, visible only on the left side of the chest, identifies a probable red organic dye [50]. It can be suggested by the conservators that a thin film of lake was applied on the entire surface of the garment and that it was partially lost over time.

IR reflectrography images show details of the painting construction such as the lines for obtaining the eyes and mouth contour and the drawings for the beard and hair, this last detail being visible on the forehead (Figure 4). The most relevant information concerns the eyes and nose drawings where the IR technique reveals the details of the original appearance which is no longer visible due to the abrasion of the final painting surface. Other details highlighted by IR images include the brush strokes of the Saint's garment, applied both vertically and horizontally, and particularly visible in the left view of the 3D model (Figure 3).

\section{Conclusions}

In the present paper, a new approach for documenting 3D sculptures during restoration activities was proposed and applied on the 17th-century reliquary bust of Saint Rodonio. To our knowledge, no other papers reported the use of digital photogrammetry for the creation of 3D models of polychromatic sculptures using ultraviolet fluorescence and infrared reflectography, making it possible to see the models on a public platform such as Sketchfab. The creation of the 3D model with the ultraviolet fluorescence and infrared reflectography of the St. Rodonio reliquary bust allowed us to respectively obtain a detailed mapping of the original materials and of the subsequent layers applied in a recent intervention, particularly visible on the head and on the chest of the saint, and the drawing used as a guide for the painting of the bust surface.

In particular, thanks to the UV model, it was possible to map all the widespread micro and macro lacunae caused by the aggressive operations for removing the faux layer of purple-like material which was carried out in the past to restore the original painting. The knowledge of the surface conservation status is highly relevant for restoration work because it allows conservators to address the proper cleaning operations and also to plan the entire restoration process. Furthermore, it is fundamentals to understanding the conservation history of the artifact. Infrared reflectography images highlighted details of the painting construction, visible especially in the Saint's face (eyes and mouth), and the brush strokes on the garment. This technique confirmed the presence of abraded areas, especially on the face of the Saint, where IR allowed for better observation of the eyes contour and lines defining the nose and the mouth.

In conclusion, the ultraviolet fluorescence and IR 3D models of the Saint Rodonio bust were particularly useful as documentation tools for the conservation status and for the painting construction. They allowed us to perfectly map the original and restoration materials and to detect the hidden drawings using single dynamic 3D files following a totally non-invasive, cost-effective and rapid imaging approach. 
Author Contributions: Conceptualization, L.L. and C.P.; methodology, L.L. and G.A.; software, L.L. and G.A.; validation, L.L. and G.A.; investigation, C.P., L.L. and G.A.; resources, C.P.; data curation, L.L.; writing-original draft preparation, C.P.; writing-review and editing, C.P., L.L. and G.A.; visualization, L.L.; supervision, C.P.; project administration, C.P.; funding acquisition, C.P.

Funding: This research was partially founded by Lazio Region (Grant No. G06970, 30 May 2018) for the Project ADAMO.

Acknowledgments: The authors would like to thank the Society Archeoares, that runs the Museum of Colle del Duomo of Viterbo, for having allowed to investigate the bust. Conservation and restoration operations, still in progress, are performed on the reliquary bust of Saint Rodonio within the training activities of the master degree course in Conservation and Restoration of Cultural Heritage of University of Tuscia, department DIBAF).

Conflicts of Interest: The authors declare no conflict of interest.

\section{References}

1. Grifoni, E.; Legnaioli, S.; Lorenzetti, G.; Pagnotta, S.; Palleschi, V. Image based recording of three-dimensional profiles of paint layers at different wavelengths. Eur. J. Sci. Theol. 2017, 13, 127-134.

2. Grifoni, E.; Legnaioli, S.; Nieri, P.; Campanella, B.; Lorenzetti, G.; Pagnotta, S.; Poggialini, F.; Palleschi, V. Construction and comparison of $3 \mathrm{D}$ multi-source multi-band models for cultural heritage applications. J. Cult. Herit. 2018, 34, 261-267. [CrossRef]

3. Soler, F.; Melero, F.J.; Luzón, M.V. A complete 3D information system for cultural heritage documentation. J. Cult. Herit. 2017, 23, 49-57. [CrossRef]

4. Stylianidis, E.; Remondino, F. (Eds.) 3D Recording, Documentation and Management of Cultural Heritage; Whittles Publishing: Scotland, UK, 2016.

5. Guarnieri, A.; Pirotti, F.; Vettore, A. Cultural heritage interactive 3D models on the web: An approach using open source and free software. J. Cult. Herit. 2010, 11, 350-353. [CrossRef]

6. Yastikli, N. Documentation of cultural heritage using digital photogrammetry and laser scanning. J. Cult. Herit. 2007, 8, 423-427. [CrossRef]

7. Yilmaz, H.M.; Yakar, M.; Gulec, S.A.; Dulgerler, O.N. Importance of digital close-range photogrammetry in documentation of cultural heritage. J. Cult. Herit. 2007, 8, 428-433. [CrossRef]

8. Apollonio, F.I.; Basilissi, V.; Callieri, M.; Dellepiane, M.; Gaiania, M.; Ponchio, F.; Rizzo, F.; Rubino, A.R.; Scopigno, R.; Sobra, G. A 3D-centered information system for the documentation of a complex restoration intervention. J. Cult. Herit. 2018, 29, 89-99. [CrossRef]

9. Pelosi, C.; Calienno, L.; Fodaro, D.; Borrelli, E.; Rubino, A.R.; Sforzini, L.; Lo Monaco, A. An integrated approach to the conservation of a wooden sculpture representing Saint Joseph by the workshop of Ignaz Günther (1727-1775): Analysis, laser cleaning and 3D documentation. J. Cult. Herit. 2016, 17, 114-122. [CrossRef]

10. Colantonio, C.; Pelosi, C.; D’Alessandro, L.; Sottile, S.; Calabrò, G.; Melis, M. Hypercolorimetric Multispectral Imaging (HMI) system for cultural heritage diagnostics: An innovative study for copper painting examination. Eur. Phys. J. Plus 2018, 133, 1-12. [CrossRef]

11. UNI-EN16095. Conservation of Cultural Property: Condition Recording for Movable Cultural Heritage; Italian Standard: Milano, Italy, 2012.

12. Pavlidis, G.; Koutsoudis, A.; Arnaoutoglou, F.; Tsioukas, V.; Chamzas, C. Methods for 3D digitization of cultural heritage. J. Cult. Herit 2007, 8, 93-98. [CrossRef]

13. Agosto, E.; Bornaz, L. 3D Models in Cultural Heritage: Approaches for Their Creation and Use. Int. J. Comput. Methods Herit. Sci. 2017, 1, 1-9. [CrossRef]

14. Xiao, W.; Mills, J.; Guidi, G.; Rodríguez-Gonzálvez, P.; Gonizzi Barsanti, S.; González-Aguilera, D. Geoinformatics for the conservation and promotion of cultural heritage in support of the UN Sustainable Development Goals. ISPRS J. Photogramm. 2018, 142, 389-406. [CrossRef]

15. Poldi, G.; Villa, G.C.F. Dalla Conservazione Alla Storia dell'arte. Riflettografia e Analisi non Invasive per lo Studio dei Dipinti; Edizioni la Normale: Pisa, Italy, 2006; pp. 19-239.

16. Cosentino, A. Practical notes on ultraviolet technical photography for art examination. Conservar Património 2015, 21, 53-62. [CrossRef] 
17. Pelagotti, A.; Pezzati, L.; Bevilacqua, N.; Vascotto, V.; Reillon, V.; Daffara, C. A study of UV fluorescence emission of painting materials. In Proceedings of the Art'05 8th International Conference on Non-Destructive Testing and Microanalysis for the Diagnostics and Conservation of the Cultural and Environmental Heritage, Lecce, Italy, 15-19 May 2005.

18. Lanteri, L.; Abramo, C. Low cost 3D documentation system applied to the bas-reliefs by Agostino di Duccio in Santo Sepolcro Cathedral at Acquapendente. Eur. J. Sci. Theol. 2018, 14, 173-180.

19. Lanteri, L.; Agresti, G. Ultraviolet fluorescence 3D models for diagnostics of cultural heritage. Eur. J. Sci. Theol. 2017, 13, 35-40.

20. Remondino, F.; Spera, M.G.; Nocerino, E.; Menna, F.; Nex, F. State of the art in high density image matching. Photogram. Rec. 2014, 29, 144-166. [CrossRef]

21. Cosentino, A. Infrared Technical Photography for Art Examination. e-Preserv. Sci. 2016, 13, 1-6.

22. Davies, A. Digital Ultraviolet and Infrared Photography; Routledge: New York, NY, USA, 2018.

23. Verhoeven, G. Imaging the invisible using modified digital still cameras for straightforward and low-cost archaeological near-infrared photography. J. Archaeol. Sci. 2008, 35, 3087-3100. [CrossRef]

24. Beraldin, J.-A.; Blais, F.; Boulanger, P.; Cournoyer, L.; Domey, J.; El-Hakim, S.F.; Godin, G.; Rioux, M.; Taylor, J. Real world modelling through high resolution digital 3D imaging of objects and structures. ISPRS J. Photogramm. 2000, 55, 230-250. [CrossRef]

25. Pollefeys, M.; Koch, R.; Vergauwen, M.; Van Gool, L. Automated reconstruction of 3D scenes from sequences of images. ISPRS J. Photogramm. 2000, 55, 251-267. [CrossRef]

26. Pieraccini, M.; Guidi, G.; Atzeni, C. 3D digitizing of cultural heritage. J Cult. Herit. 2001, 2, 63-70. [CrossRef]

27. De Reu, J.; Plets, G.; Verhoeven, G.; De Smedt, P.; Bats, M.; Cherretté, B.; De Maeyer, W.; Deconynck, J.; Herremans, D.; Laloo, P.; et al. Towards a three-dimensional cost-effective registration of the archaeological heritage. J. Archaeol. Sci. 2013, 40, 1108-1121. [CrossRef]

28. Scopigno, R.; Callieri, M.; Cignoni, P.; Corsini, M.; Dellepiane, M.; Ponchio, F.; Ranzuglia, G. 3D models for cultural heritage: Beyond plain visualization. Computer 2011, 44. [CrossRef]

29. Guidi, G.; Russo, M.; Angheleddu, D. 3D survey and virtual reconstruction of archeological sites. Digital Appl. Archaeol. Cult. Herit. 2014, 1, 55-69. [CrossRef]

30. Luhmann, T.; Fraser, C.; Maas, H.-G. Sensor modelling and camera calibration for close-range photogrammetry. ISPRS J. Photogramm. 2016, 115, 37-46. [CrossRef]

31. Karabörk, H.; Yaldiz, E.; Karasaka, L. 3D documentation of portal muqarnases in Anatolian Madrasahs with digital close range photogrammetric method. Mediterr. Archaeol. Ar. 2017, 17, 137-148. [CrossRef]

32. Ortiz-Cordero, R.; Hidalgo Fernánde, R.E. 3D Photogrammetry, capacity, filling time and water flow simulation of Cordoba's Mosque-Cathedral Islamic cistern. Digital Appl. Archaeol. Cult. Herit. 2017, 4, 39-48. [CrossRef]

33. Pintando, J.A.; Serrano Basterra, P. Contributions of the digital photogrammetry and 3D modelling of Roman inscriptions to the reading of damaged tituli: An example from the Hispania Tarraconensis (Castiliscar, Saragossa). Digital Appl. Archaeol Cult. Herit. 2019. [CrossRef]

34. Remondino, F.; Menna, F. Image-based surface measurement for close-range heritage documentation. International Archives of Photogrammetry. Remote Sens. Spat. Inf. Sci. 2008, 37, 199-206.

35. Remondino, F. Heritage recording and 3D modeling with photogrammetry and 3D scanning. Remote Sens. 2011, 3, 1104-1138. [CrossRef]

36. Remondino, F.; El-Hakim, S. Image-based 3D modelling: A review. Photogram. Rec. 2006, 21, $269-291$. [CrossRef]

37. Montevecchi, B.; Vasco Rocca, S. (Eds.) Dizionari Terminologici, Suppellettile Ecclesiastica I; Centro Di: Florence, Italy, 1988; Volume 4, pp. 157-161. 192p.

38. Agresti, G.; Lanteri, L.; Pelosi, C.; Benucci, M.; Caldi, C.; Scioscia, S. Tecnologie integrate per la documentazione, la diagnostica e per il restauro del busto reliquarion di San Rodonio, dal Museo Colle del Duomo di Viterbo. In Lo Stato dell'Arte, Proceedings of the 15th National Conference IGIIC, Bari, Italy, 12-14 October 2017; Nardini Editore: Florence, Italy, 2017; pp. 445-451.

39. Howland, M.D.; Kuester, F.; Levy, T.E. Photogrammetry in the field: Documenting, recording, and presenting archaeology. Mediterr. Archaeol. Archaeom. 2014, 14, 101-108.

40. Lowe, G. Distinctive Image Features from Scale-Invariant Keypoints. Int. J. Comput. Vis. 2004, 60, 91-110. [CrossRef] 
41. Measday, D. A Summary of Ultra-Violet Fluorescent Materials Relevant to Conservation. 2017. Available online: https:/ / aiccm.org.au/national-news/summary-ultra-violet-fluorescent-materials-relevant-conservation (accessed on 30 August 2018).

42. Cosentino, A. Effects of different binders on technical photography and infrared reflectography of 54 historical pigments. Int. J. Conserv. Sci. 2015, 6, 287-298.

43. De la Rie, E.R. Fluorescence of Paint and Varnish Layers (Part II). Stud. Conserv. 1982, 27, 65-69.

44. De la Rie, E.R. Fluorescence of Paint and Varnish Layers (Part III). Stud. Conserv. 1982, 27, 102-108. [CrossRef]

45. Derrick, M. Fourier transform infrared spectral analysis of natural resins used in furniture finishes. J. Am. Inst. Conserv. 1989, 28, 43-56. [CrossRef]

46. Aligizaki, E.M.; Melessanaki, K.; Pournou, A. The use of lasers for the removal of shellac from wood. e-Preserv. Sci. 2008, 5, 36-40.

47. Coelho, C.; Raviteja, N.; Matthieu, M.; Sophie, C.; Verney, V. Molecular changes during natural biopolymer ageing. The case of shellac. Polym. Degrad. Stab. 2012, 97, 936-940. [CrossRef]

48. Bernikola, E.; Melessanaki, K.; Hatzigiannakis, K.; Tornari, V.; Pouli, P. Real-time monitoring of laser-assisted removal of shellac from wooden artefacts using digital holographic speckle pattern interferometry. In Lasers in the Conservation of Artworks IX; Saunders, D., Strlič, M., Korenberg, C., Luxford, N., Birkhölzer, K., Eds.; Archetype: London, UK, 2013; pp. 52-58.

49. Capobianco, G.; Calienno, L.; Pelosi, C.; Scacchi, M.; Bonifazi, G.; Agresti, G.; Picchio, R.; Santamaria, U.; Serranti, S.; Lo Monaco, A. Protective behaviour monitoring on wood photo-degradation spectroscopic techniques coupled with chemometrics. Spectrochim. Acta A 2017, 172, 34-42. [CrossRef]

50. De la Rie, E.R. Fluorescence of Paint and Varnish Layers (Part I). Stud. Conserv. 1982, 27, 1-7.

(C) 2019 by the authors. Licensee MDPI, Basel, Switzerland. This article is an open access article distributed under the terms and conditions of the Creative Commons Attribution (CC BY) license (http:// creativecommons.org/licenses/by/4.0/). 